\title{
LA REINSERCIÓN SOCIAL Y EL PRINCIPIO DE PROPORCIONALIDAD
}

\author{
Social Reintegration and the Principle of Proportionality
}

\section{Maximiliano HERNÁNDEZ CUEVAS*}

\begin{abstract}
Sumario:
I. Introducción II. El concepto jurídico de reinserción social de sentenciados III. El concepto de reinserción social en documentos internacionales; IV. La reinserción social en el contexto jurídico constitucional federal y local V. La reinserción social en la Ley Nacional de Ejecución Penal VI. La pena privativa de la libertad y la reinserción social ante el examen de proporcionalidad VII. Conclusiones.
\end{abstract}

Resumen: Este estudio contribuye a esclarecer el concepto de reinserción social de sentenciados a prisión como un derecho fundamental de prestación y sus posibilidades de ejercicio. Resignificarlo así involucra un mejor y más efectivo uso de las alternativas penales para que la práctica de tal derecho sea posible dentro y fuera de la prisión. Finalmente, se expone que, al concebir a la reinserción social como fin de la pena, la aplicación de ésta no resiste el examen de proporcionalidad.

Palabras clave: prisión, reinserción social, principio, proporcionalidad, derechos humanos

Abstract: This study contributes to clarify the concept of social reintegration of sentenced to prison as a fundamental right of benefit and its possibilities for exercise. Resignifying it thus involves a better and more effective use of criminal alternatives so that the practice of such right is possible in and out of prison. Finally, it is stated that, in conceiving of social reintegration as the end of grief, the application of the sentence does not withstand the proportionality test.

Keywords: Prison, Social Reintegration, Principle, Proportionality, Human Rights

\section{Introducción}

La hipótesis punto de partida del siguiente desarrollo es la siguiente:

En nuestro país el concepto de reinserción social de sentenciados penalmente es impreciso en la Constitución Federal; y a nivel local, en la Constitución de la Ciudad de México, aunque se le reconoce como un derecho, su contenido también resulta difuso y equívoco. Esto se debe, primordialmente, a que tal concepto es concebido como finalidad de la pena privativa de la libertad y no en calidad de derecho de prestación reclamable por los reclusos.

Tal aseveración ensaya una respuesta preliminar a diversas interrogantes que surgen cuando se busca el sentido actual de la pena privativa de la libertad, tales como: ¿es ésta una institución

\footnotetext{
* Profesor Investigador de la Universidad Autónoma de la Ciudad de México, catedrático y fundador de la Licenciatura en Derecho en el Programa Universitario de Educación Superior en Centros de Reclusión de la Ciudad de México (PESCER), impartida a los reclusos. 
cuyo fin es la reinserción social de los penados, más que la protección de los derechos de las personas víctimas del delito? ¿Es posible aprovechar su tiempo de duración para administrarles a los detenidos un tratamiento que coadyuve al logro de dicha reinserción? ¿Qué significa la reinserción social como principio dispuesto constitucionalmente? ¿Cuándo cabe hablar de reinserción, mientras los titulares de tal derecho están presos o hasta que son excarcelados? ¿Cabe considerar el ejercicio de derechos fundamentales como un medio para lograr la pretendida reinserción social?

Dar respuesta íntegra a las interrogantes previas rebasa los límites del presente estudio, sin embargo, ello no supone la imposibilidad de responderlas aquí al punto de exponer las insuficiencias y equívocos respecto al principio constitucional de la reinserción social de sentenciados tal como se ha dispuesto, de un lado, en la Constitución Federal y, de otro, en la Constitución de la Ciudad de México. En ese empeño, el objetivo de este trabajo es analizar dicho principio y esgrimir argumentos que reivindiquen su calidad de derecho fundamental, para demostrar que como ahora está dispuesto su contenido carece de una especificidad que permita reconocerlo como tal, lo cual es necesario a efecto de proteger su efectiva realización y, en su caso, evitar los excesos punitivos en la aplicación de la pena privativa de libertad.

En otras palabras, se pretende contribuir a esclarecer que el derecho a la reinserción social, dada su actual definición en la Constitución Federal y, a su vez, en la Constitución de la Ciudad de México -con sus particulares asertos-, precisa de una reconceptualización sin contenidos teleológicos, en la cual se asuma que la pena de prisión, dadas sus propias características, afecta la integridad psicofísica de los penados; y que, por lo mismo, necesita -básicamente- organizarse para protegerla promoviendo la práctica de los derechos fundamentales no limitados por el castigo. Esto, asimismo, considerando a la reinserción social como un derecho exigible por los sentenciados y no como finalidad de la pena.

\section{El concepto jurídico de reinserción social de sentenciados}

No obstante que la teoría de la personalidad delincuencial resulta anacrónica -lo mismo que su correspondiente perspectiva político-criminal, promotora de una institución carcelaria con la cual se ha pretendido reformar a los reclusos con un tratamiento de corte terapéutico ${ }^{1}-$, y pese a la evidencia empírico-teórica que prueba lo contrario², todavía así, en la legislación internacional y nacional sobre el tema sigue vigente tal idea. Para ello se ha colocado el concepto de

\footnotetext{
1 Presuntamente útil para reintegrarlos a la vida social como individuos productivos no reincidentes en comportamientos delictivos.

2 Es decir, el fracaso de la prisión en funciones y fines de rehabilitación. Sobre el tema véase, por ejemplo, ENRÍQuez Rubio Hernández, Herlinda, (2016), El pluralismo jurídico intracarcelario. El derecho y la ley no escrita de la prisión, México, Porrúa, $2^{\text {a }}$ ed. véanse capítulos 2 y 3; BARATTA, Alessandro (2004), Criminología crítica y crítica del derecho penal. Introducción a la sociología jurídico-penal, Buenos Aires, Siglo XXI, $1^{\mathrm{a}}$ ed., $1^{\mathrm{a}}$ Reimpresión, pp.193-218; Orellana Wiarco, Octavio (2012), Criminología moderna y contemporánea, México, Porrúa, pp. 211-225; Miralles, Teresa, (1983), "IV Patología criminal: La personalidad criminal”, en Bergali, R, et al, Pensamiento criminológico I: un análisis crítico, Bogotá, Colombia, Temis, pp. 69-90; Hernández Cuevas, Maximiliano (2011), Trabajo y derecho en la prisión. Una relación entre legalidad y normatividad alterna, México, Porrúa, véanse capítulos 4 a 6; Cullen, Francis y Gendreau, Paul (2006), "Evaluación de la rehabilitación correccional: política, prácticas y perspectivas", en BARBERET, Rosemary y BARQuín, Jesús, Justicia penal siglo XXI. Una selección criminal justice 200o, Granada, National Institute of Justice (U.S. Department of justice), pp. 275-348; GARland, David, (2005), La cultura del control. Crimen y orden social en la sociedad contemporánea, Barcelona, Gedisa, pp. 235-276; Hassemer, Winfried y Muñoz Conde Francisco (1989), Introducción a la criminología y al derecho penal, Valencia, tirant lo blanch, pp. 135-146; FERrAJOLI, Luigi (1995), Derecho y razón. Teoría del garantismo penal, Madrid, Trotta, pp. 506-509.
} 
reinserción social en sustitución de otros previos -como los de rehabilitación o readaptación-, rodeándolo de una visión jurídica en la cual, aunque se hace referencia a un tratamiento de los sentenciados a pena de prisión, éste ha sido desligado de sus rasgos curativos (con los que se buscaba rehabilitarlos en un régimen penitenciario progresivo y técnico ${ }^{3}$ ).

De tal modo, se conserva la idea central reformista de la pretendida personalidad criminal, pero sin recurrir a nociones terapéuticas. Es decir, sobre la base de administrar a los internos tratamientos orientados a la práctica de sus derechos, aquellos que no les han sido restringidos por la pena privativa de la libertad. El resultado: la justificación de que la pena de prisión puede contribuir a su reinserción a la vida en sociedad procurando que no vuelvan a reincidir, ahora con base en la práctica de los derechos humanos ${ }^{4}$.

Así, establecida la liga entre derechos fundamentales no limitados a los reclusos durante su encarcelamiento y su reinserción social, procede analizar cómo ésta es conceptualizada jurídicamente, primero a nivel internacional y después en el nacional mexicano.

\section{El concepto de reinserción social en documentos internacionales}

En la reconocida Carta de Derechos Humanos ${ }^{5}$ el tema de la pena de prisión y sus fines se enuncia como sigue:

\section{Artículo $10^{6}$}

1. Toda persona privada de libertad será tratada humanamente y con el respeto debido a la dignidad inherente al ser humano (...)

3. El régimen penitenciario consistirá en un tratamiento cuya finalidad esencial será la reforma y la readaptación social de los penados (...)

Nótese que el numeral 1 contiene la porción nuclear del derecho fundamental consagrado en el artículo y que el numeral 3 contribuye a definirlo: se afirma que las personas privadas de su

3 Ley que Establece las normas Mínimas sobre Readaptación Social de Sentenciados, derogada a partir del 16 de junio de 2016: "ARTICULO 70.- El régimen penitenciario tendrá carácter progresivo y técnico y constará, por lo menos, de períodos de estudio y diagnóstico y de tratamiento, (...)".

4 Puede afirmarse que el término "técnico" es un puente entre la visión terapéutica que refiere a un cuerpo interdisciplinario de especialistas en diversas ramas del saber científico, antes concebidos en calidad de terapeutas (encargados de hacer un diagnóstico y prescribir un tratamiento progresivo y técnico de carácter reformador de la personalidad), y, ahora, como prestadores de servicios ofrecidos a los internos, lo que representa la garantía de que puedan ejercer sus derechos fundamentales no limitados con la prisión. Esto marca una importante diferencia de fondo, sin embargo, el cambio de orientación se trastoca al no organizar una práctica de los derechos humanos per se, es decir, valorada por su peso propio, sino degradándola a un medio para lograr la reinserción social.

5 Se conoce así al conjunto fundacional y jerárquicamente más importante de instrumentos jurídicos sobre derechos humanos en el contexto internacional, constituido por la Declaración Universal de los Derechos Humanos de 1948, el Pacto Internacional de Derechos Civiles y Políticos y sus protocolos facultativos (1966), y el Pacto Internacional de Derechos Económicos Sociales y Culturales (Adopción en 1966).

6 Organización De Las Naciones Unidas, Pacto Internacional de Derechos Civiles y Políticos, Nueva York, 1966 (adhesión de México el 24 de marzo de 1981). Se destaca en cursivas lo que ocupa nuestro análisis. 
libertad serán tratadas humanamente y esto, necesariamente, lleva a considerar como parte de ello al tratamiento o régimen cuya finalidad es la reforma y readaptación social de los penados.

De igual forma, conviene advertir que esta disposición, perteneciente a un tratado jurídico de primordial jerarquía a nivel internacional, define lo que ha de entenderse por régimen penitenciario y sus finalidades. Lo hace, como podrá inferirse de la terminología empleada (tratamiento, reforma y readaptación), bajo el criterio reformista y rehabilitador más arriba mencionado; idea que científicamente ha caducado, pero que en dicho convenio se mantiene vigente. Vemos aquí un asunto relevante: que el tratamiento o régimen penitenciario, y los fines de reforma y readaptación social constituyen parte del derecho fundamental consagrado en el Pacto, aun cuando esto resulta una paradoja, como veremos.

En igual circunstancia se encuentra lo expresado en la Convención Americana sobre Derechos Humanos, de origen y cobertura regional, que acorde con el contenido del Pacto antes citado dispone:

Artículo 5.- Derecho a la Integridad Personal

1. Toda persona tiene derecho a que se respete su integridad física, psíquica y moral.

2. Nadie debe ser sometido a torturas ni a penas o tratos crueles, inhumanos o degradantes. Toda persona privada de libertad será tratada con el respeto debido a la dignidad inherente al ser humano (...)

6. Las penas privativas de la libertad tendrán como finalidad esencial la reforma y readaptación social de los condenados?.

En este caso, la reforma y readaptación social contribuyen a definir el Derecho a la Integridad Personal, y con ello, como en el caso anterior, adquieren calidad de derecho aun cuando esto también sea cuestionable.

Lo paradójico de que la reforma y readaptación social queden enmarcadas como derecho fundamental estriba en que los derechos fundamentales son estrictamente potestades de extracción deóntica y no axiológica, principios que -por esto mismo- no admiten orientación teleológica ${ }^{8}$, tal como se atribuye a la reforma y readaptación al conceptualizarlos como finalidad esencial de las penas privativas de la libertad. Advertimos así una importante inconsistencia producida al ubicar como valores a los derechos fundamentales ${ }^{9}$, cuando epistémicamente su carácter es el de principios. Es decir, resulta erróneo definirlos por medio de finalidades (en este caso la reforma y la readaptación social), pues se afecta su calidad categórica -de obligatoriedad-y se les degrada a una aspiración que puede o no ser cumplida ${ }^{10}$.

En el caso de la Convención, además, sin referir al régimen penitenciario -el cual dentro del Pacto significa tratamiento-, se rescata que Toda persona privada de libertad será tratada

7 Convención Americana sobre Derechos Humanos (Pacto de San José), San José, Costa Rica, 7 de mayo de 1981. Se destaca en cursivas lo que ocupa nuestro análisis.

8 Los principios son de cuño deontológico, en cambio, los valores son de origen axiológico y, por ende, se orientan a finalidades.

9 En el Pacto, a un trato humano y respetuoso de la dignidad y, en la Convención, a la integridad personal.

10 Sobre el tema de los valores y principios en el sentido expuesto, véase Habermas, Jürgen (2005), Facticidad y validez. Sobre el derecho y el Estado democrático de derecho en términos de teoría del discurso, Madrid, Trotta, $4^{\mathrm{a}}$ ed., pp.328-335; Alexy, Robert (1993), Teoría de los derechos fundamentales, Madrid, Centro de Estudios Cons- 
con el respeto debido a la dignidad inherente al ser humano. Y posteriormente, en el numeral 6, aparece llanamente la pena privativa de la libertad con sus fines de reforma y readaptación. Esto último, le reconoce a dicha institución punitiva un papel en la definición del Derecho a la Integridad Personal, lo que resulta antagónico a tal cometido, pues, sustancialmente, la privación de la libertad es una agresión a la integridad psíquica y física de las personas. Y no cabe, por lo mismo, involucrarla en disposiciones de derecho fundamental que con ella no se pueden cumplir (como es el salvaguardar la integridad de la persona humana).

De tal manera, es dable apreciar inestabilidad o equivocidad en las definiciones de los derechos fundamentales analizados. Pero, simultáneamente, que aun cuando la readaptación social es integrante de esas definiciones, pese a la falta de ser ubicada como finalidad, adquiere una dimensión propia - esto es, se proyecta como derecho fundamental en ciernes, con peso propio- al tener presencia en dos documentos distintos. Un derecho en sus comienzos que, para integrarse como tal, $1^{\circ}$ precisa de una reconceptualización que abandone el sentido reformista de la personalidad $y$, seguido a esto, $2^{\circ}$ su reconocimiento de principio o norma de derecho fundamental de los condenados, exigible y practicable, en lugar de finalidad de la pena privativa de libertad o consecuencia deseable.

Más todavía, si se toma en sentido fuerte el derecho a un trato digno y respetuoso de la integridad, la posible reintegración de los penados a la vida social adquiere el carácter de derecho fundamental de prestación ${ }^{11}$, es decir, que intrínsecamente conlleva la obligación del Estado de proteger efectivamente la integridad de los penados, la cual resulta seriamente menoscabada por el encierro ${ }^{12}$. Es en esto cuando cobra importancia desprender del régimen penitenciario la idea reformadora y curativa; de ahí que en documentos actualizados el término readaptación ha sido sustituido por el de reinserción social, como enseguida veremos, dentro de una perspectiva que intenta trascender la idea terapéutica original. Revisemos de qué modo se ha manejado el tema en documentos legislativos internacionales de carácter reglamentario.

\subsection{La reinserción social a nivel reglamentario}

¿Qué acontece con la reglamentación internacional sobre las disposiciones acabadas de revisar? Es pertinente comenzar por el primer instrumento que reglamenta lo que de forma general se ha dispuesto en el Pacto Internacional de Derechos Civiles y Políticos y en la Convención Ame-

titucionales, pp. 138-172; Zagrebelsky, Gustavo, El derecho dúctil. Ley, derechos, justicia (1995), Madrid, Trotta, pp. 109-120; FARrel, Martín, “El utilitarismo en la filosofía del derecho”. En línea. Disponible en: https://archivos.juridicas.unam.mx/www/bjv/libros/8/3876/4.pdf (consultada el 2 de marzo de 2018); Cortina, Adela (200o), Ética mínima. Introducción a la filosofía práctica, Madrid, Tecnos, $6^{\mathrm{a}}$ ed., pp. 90-92.

11 “(...) los derechos de prestación son el resultado, o bien de un mandato de hacer dirigido a los poderes públicos (incluso a los particulares) contenido en la norma iusfundamental, de tal manera que de ese mandato sea posible deducir un derecho a una conducta positiva del Estado (o de los particulares), o bien de una exigencia derivada de la garantía de un efectivo y real ejercicio del derecho fundamental en cuestión (...) En sentido amplio un derecho de prestación puede ser el derecho a que el Estado regule determinada realidad”, Bastida, Francisco et al. (2004), Teoría General de los Derechos Fundamentales en la Constitución Española de 1978, Madrid, pp. 98-99. En línea. Disponible en: https://www.unioviedo.es/constitucional/miemb/alaez/librodf.PDF (consultada el $31 \mathrm{de}$ enero de 2019); “(...) Si se presupone un concepto amplio de prestación, todos los derechos a acciones positivas del Estado pueden ser calificados como derechos a prestaciones del Estado en un sentido amplio (...)”, ALEXY, Robert (1993), op. cit., nota 10, p, 419; “(...) Todo derecho a un acto positivo, es decir, a un acto del Estado es un derecho a prestaciones (...)”, Ibídem, p. 427.

${ }^{12}$ Al respecto véase, Enríquez Rubio Hernández, Herlinda (2016), op. cit., nota 2, capítulos 2, 3 y los anexos II y III; Hernández Cuevas, Maximiliano (2011), op. cit. Nota 2, capítulos 4 y 6 y anexo I; Orellana Wiarco, Octavio (2012), op. cit., nota 2, pp. 211-225. 
ricana. El documento fue actualizado en 2015 precisamente porque varias normas lo requerían, entre ellas las que ocupan el interés de nuestro análisis. Se le modificó la denominación con una añadidura: de "Reglas Mínimas de las Naciones Unidas para el Tratamiento de los Reclusos" pasó a ser nombrado también "Reglas Nelson Mandela”. Como corresponde a un instrumento actualizado, se hace un uso más cuidadoso de los conceptos y se retira del mismo la perspectiva terapéutica que aparecía en el documento original ${ }^{13}$. Veamos las reglas interesantes a nuestro análisis:

\section{Regla 4}

1. Los objetivos de las penas y medidas privativas de libertad son principalmente proteger a la sociedad contra el delito y reducir la reincidencia. Esos objetivos sólo pueden alcanzarse si se aprovecha el período de privación de libertad para lograr, en lo posible, la reinserción de los exreclusos en la sociedad tras su puesta en libertad, de modo que puedan vivir conforme a la ley y mantenerse con el producto de su trabajo.

2. Para lograr ese propósito, las administraciones penitenciarias y otras autoridades competentes deberán ofrecer educación, formación profesional y trabajo, así como otras formas apropiadas y disponibles de asistencia, incluidas las de carácter recuperativo, moral, espiritual y social y las basadas en la salud y el deporte. Todos esos programas, actividades y servicios se ofrecerán en atención a las necesidades de tratamiento individuales de los reclusos.

\section{Regla 5}

1. El régimen penitenciario procurará reducir al mínimo las diferencias entre la vida en prisión y la vida en libertad que tiendan a debilitar el sentido de responsabilidad del recluso o el respeto a su dignidad como ser humano ${ }^{14}$.

Nótese que a diferencia del Pacto y de la Convención acabados de analizar, las Reglas Mandela presentan objetivos y no fines de la pena privativa de la libertad. Evitan hablar del fin de la readaptación social de los penados y, en cambio, enuncian que los objetivos de la referida sanción son los de proteger a la sociedad contra el delito y reducir la reincidencia.

La sustitución de términos obedece, por una parte, a necesidades de actualización según se consigna en la observación preliminar 1 de este documento ${ }^{15}$, y por otra, en mi opinión, a un mejor entendimiento sobre la pena privativa de la libertad, con respecto a lo mostrado en el

\footnotetext{
${ }^{13}$ El nombre y las fechas de adopción del documento original vía sus respectivas resoluciones son: Reglas Mínimas de las Naciones Unidas para el Tratamiento de los Reclusos. Adopción: Consejo Económico y Social de la ONU. Resoluciones 663C (XXIV), del 31 de julio de 1957 y 2076 (LXII), del 13 de mayo de 1977. En su principio 59 se establece: "Para lograr este propósito, el régimen penitenciario debe emplear, tratando de aplicarlos conforme a las necesidades del tratamiento individual de los delincuentes, todos los medios curativos, educativos, morales, espirituales y de otra naturaleza, y todas las formas de asistencia de que puede disponer." Las cursivas son mías.

${ }^{14}$ Organización De Las Naciones Unidas, Reglas Mínimas de las Naciones Unidas para el Tratamiento de los Reclusos (Reglas Nelson Mandela), Asamblea General, resolución 70/175, anexo, aprobado el 17 de diciembre de 2015. Las cursivas fueron puestas por mí.

15 "Observación preliminar 1. El objeto de las siguientes reglas no es describir en forma detallada un sistema penitenciario modelo, sino únicamente enunciar, partiendo de los conceptos generalmente aceptados en nuestro tiempo y de los elementos esenciales de los sistemas contemporáneos más adecuados, los principios y prácticas que hoy en día se reconocen como idóneos en lo que respecta al tratamiento de los reclusos y la administración penitenciaria.", Ídem.
} 
Pacto y la Convención citados anteriormente, pero que aún no libra los equívocos. Las Reglas reconceptualizan el fin de la pena privativa de la libertad como objetivos: proteger del delito y reducir la reincidencia ${ }^{16}$.

No obstante, ¿de qué manera se maneja la idea si no de readaptar, la de hacer algo con los penados? En el numeral 1 de la Regla 4, se prescribe un aprovechamiento del periodo de reclusión (...) para lograr, en lo posible, la reinserción de los exreclusos en la sociedad (... $)^{17}$ En efecto, el concepto de reinserción social aparece por primera vez en la historia de ese documento reglamentario. Pero adviértase que se utiliza para el caso de los exreclusos y no antes, pues resulta pertinente hablar de reinserción una vez que los penados han logrado su libertad. Y aparece como un propósito que ayudará, a su vez, al logro de los objetivos de protección a la sociedad y reducción de la reincidencia, si se aprovecha el tiempo de duración de la pena.

Entonces, ¿el significado de reinserción dado en la Regla 4, se vincula así al periodo de internamiento? Al legislar esto la Asamblea de la ONU consigue no declarar que la reinserción es el fin de la pena privativa de libertad, pero indirectamente conserva esta finalidad al condicionar el logro de los objetivos de protección y reducción de la reincidencia a lo que se haga en el periodo de duración de la pena, con lo que se continúa con la idea de reformar la personalidad de los reclusos. No obstante, el uso de la expresión lograr en lo posible revela que la reinserción social se concibe con incertidumbre. Implica duda sobre el resultado de aquello que pudiera efectuarse en el periodo de aplicación de la pena con el propósito (enunciado así en el numeral 2) de que los exreclusos no delincan y sean capaces de vivir de su trabajo.

Cabe decir que el concepto reinserción social es, de entrada, definido con propiedad porque se aplica al caso de los exreclusos, pero se le vuelve equívoco al involucrar aquello a realizar con el penado en cautiverio. En tal sentido, se conserva la idea del tratamiento de los reclusos como parte de su proceso de reinserción, lo cual conduce a una interrogante incontestable de manera afirmativa en el contexto de los hechos: ¿qué tanto es posible la reinserción de los internos, en los términos prescritos, aun cuando el régimen penitenciario procure reducir al mínimo las diferencias entre la vida en prisión y la vida en libertad?

Tal problemática proviene del error que implica orientar a fines o propósitos tanto al trato digno a los reclusos (el cual es un principio, no un medio dirigido a un propósito reformador), como a la reinserción social de los exreclusos, misma que precisa ser reconocida en su carácter de derecho fundamental de prestación, que obliga al Estado a hacer lo necesario para que dicha potestad se ejerza plenamente por las personas que ya cumplieron una pena privativa de liber-

\footnotetext{
${ }^{16}$ Esto, aunque la evidencia empírica demuestra que la prisión no protege a la sociedad, dados los niveles de impunidad y de reincidencia delictiva; igualmente demuestra, y con mayor contundencia, que tampoco puede reformar y rehabilitar a los reclusos. Este es todo un tema en el problema de los fines y justificación de la pena privativa de libertad que en el terreno formal y teórico no se consigue resolver, como podemos advertir en las contradicciones normativas apuntadas: el fin de la pena de prisión ¿es la reforma y readaptación de los penados? o acaso ¿la protección de la sociedad en contra del delito y su reincidencia? Las diferentes teorías de la pena han fracasado en el intento de justificar la aplicación del derecho penal, eso es constatable en la literatura que sobre el tema ha realizado una cuidadosa crítica. Así, el escabroso asunto de la justificación del derecho penal, y de la pena de prisión en particular, ha sido resuelto no en el terreno jurídico ni en el teórico-penal, sino en el de la filosofía del derecho: la única justificación posible de la existencia y aplicación derecho penal es la protección de los derechos humanos. Al respecto, véase Ferrajoli, Luigi (1995), op. cit., nota 2, pp. 335-336; FerRAJOLI, Luigi (2004), Epistemología jurídica y garantismo penal, México, Fontamara, pp. 283-299; BARATTA, Alessandro (2004), op. cit., nota 2, pp.227-241.

17 Organización De Las Naciones Unidas, Reglas Mínimas de las Naciones Unidas para el Tratamiento de los Reclusos (Reglas Nelson Mandela), Asamblea General, resolución 70/175, anexo, aprobado el 17 de diciembre de 2015, Regla 4 numeral 1.
} 
tad. Esto es, que logren un autosostén digno y no reciban un trato proclive a la marginación o al estigma dentro de la vida social.

Ahora bien, para acceder a posturas como la anterior, es imperioso la existencia de estatutos en los que se logre dimensionar con precisión el carácter de principios de las normas organizadoras de los regímenes penitenciarios; evitar equivocidades como las observadas en los instrumentos hasta ahora revisados. En tal sentido, podemos apreciar otro documento internacional: Los principios básicos para el tratamiento de los reclusos ${ }^{18}$ cuya perspectiva acerca del trato a los privados de la libertad es notablemente distinta, pues alejada de la prescripción de tratamientos reformistas de la personalidad, en cambio, se centra en la realización de principios -en su caso, derechos fundamentales:

1. Todos los reclusos serán tratados con el respeto que merecen su dignidad y valor inherentes de seres humanos $(\ldots)$

5. Con excepción de las limitaciones que sean evidentemente necesarias por el hecho del encarcelamiento, todos los reclusos seguirán gozando de los derechos humanos y las libertades fundamentales consagrados en la Declaración Universal de Derechos Humanos y, cuando el Estado de que se trate sea parte, en el Pacto Internacional de Derechos Económicos, Sociales y Culturales y el Pacto Internacional de Derechos Civiles y Políticos y su Protocolo Facultativo, así como de los demás derechos estipulados en otros instrumentos de las Naciones Unidas.

6. Todos los reclusos tendrán derecho a participar en actividades culturales y educativas encaminadas a desarrollar plenamente la personalidad humana (...)

8. Se crearán condiciones que permitan a los reclusos realizar actividades laborales remuneradas y útiles que faciliten su reinserción en el mercado laboral del país y les permitan contribuir al sustento económico de su familia y al suyo propio (...)

10. Con la participación y ayuda de la comunidad y de instituciones sociales, y con el debido respeto de los intereses de las víctimas, se crearán condiciones favorables para la reincorporación del exrecluso a la sociedad en las mejores condiciones posibles.

Es destacable que las disposiciones tienen el carácter de principios y no de valores orientados a fines, esto es, se mantienen en el ámbito deóntico y no en el axiológico, lo cual transforma profundamente lo que se considera debe hacerse con los reclusos en prisión, es decir:

$1^{\circ}$, Se da un giro al sentido del régimen penitenciario: de basarse éste en disposiciones normativas dirigidas al logro de finalidades, objetivos y propósitos, se cambia a principios que ordenan el ejercicio de los derechos fundamentales no limitados por la pena, en un entorno respetuoso de la dignidad humana (principios 1 y 5 ). $2^{\circ}$, por lo mismo, se habla de trato y no de tratamiento de los penados (principio 1).

$3^{\circ}$, El derecho a participar en actividades culturales y educativas (principio 6), implica que éstas se reconocen y protegen en su calidad de derechos fundamentales de prestación, pues el

\footnotetext{
18 Organización De Las Naciones Unidas, Principios básicos para el tratamiento de los reclusos, Adopción: Asamblea General de la ONU, Resolución 45/111, 14 de diciembre de 1990.
} 
Estado queda obligado a garantizar la provisión de los insumos necesarios para la realización de dichas actividades (derechos a la cultura y a la educación).

$4^{\circ}$, Respecto al mismo principio, la realización efectiva e integral de los derechos fundamentales permite pensar en un posible y pleno desarrollo de la personalidad en cualquier ser humano. Pero ello se funda en la práctica de derechos humanos, no en la prescripción de tratamientos individuales encaminados a fines con pretensiones reformistas de la personalidad.

$5^{\circ}$, En igual sentido, el principio 8 hace referencia a derechos fundamentales de prestación de tipo laboral, en lo que el Estado queda obligado a hacer lo conducente para la realización de tales potestades de los reclusos. Práctica que facilite su reinserción en el mercado laboral y permita contribuir al sustento familiar y el propio. Obsérvese que aquí, nuevamente, aparece condicionado el ejercicio de derechos a finalidades de reinserción; lo cual hace patente la dificultad de separar la práctica de un derecho fundamental dentro de la prisión, de los resultados que de ello pudieran derivarse. Tenemos pues, el mismo desacierto de los documentos precedentes: orientar el ejercicio de un derecho fundamental a fines, con lo cual dicha práctica se convierte en un medio, cuando propiamente es un principio. La obligación del Estado, sobre todo hacia quienes son separados de la sociedad por la fuerza, es garantizar el pleno ejercicio de sus derechos humanos, aquellos no restringidos por la pena de prisión, independientemente si de ello se desprenden o no consideraciones de utilidad como pueden ser la reinserción y el autosostén.

$6^{\circ}$, El principio 10 también estatuye un derecho de prestación: el derecho fundamental a la reinserción social de los exreclusos. Es en este caso cuando procede la práctica de tal potestad al tratarse de la pena privativa de la libertad, es decir, cuando la referencia es a exreclusos. En internamiento el ejercicio de este derecho es impracticable en los términos normativos actuales; $y$, sin embargo, reclamable ¿pero hasta qué punto? En esto último, radica la problemática de los fines de la pena privativa de libertad. Si su finalidad es la reinserción social, la práctica de derechos humanos se reduce a un medio para conseguirla, lo cual resulta inviable epistemológicamente porque los derechos humanos son principios y no medios. En cambio, si la reinserción social se asume como derecho de prestación, entonces se vuelve no una aspiración, sino un principio exigible por los reclusos, pero esto, según lo permita su limitación punitiva y proporcional de derechos fundamentales impuesta por la pena de prisión. Asunto que enseguida abordaremos.

\section{La reinserción social en el contexto jurídico constitucional federal y local}

En el texto vigente de la Constitución Política de los Estados Unidos Mexicanos, el concepto de reinserción social aparece como sigue:

El sistema penitenciario se organizará sobre la base del respeto a los derechos humanos, del trabajo, la capacitación para el mismo, la educación, la salud y el deporte como medios para lograr la reinserción del sentenciado a la sociedad y procurar que no vuelva a delinquir, observando los beneficios que para él prevé la ley. Las mujeres compurgarán sus penas en lugares separados de los destinados a los hombres para tal efecto ${ }^{19}$.

Puede observarse que se ordena la organización del sistema penitenciario sobre la base del respeto a los derechos humanos en general y, entre ellos, en particular, al trabajo, la capacitación, la educación, la salud y al deporte. De esto, es importante subrayar que tales derechos

19 Cámara De Diputados Del H. Congreso De La Unión, Constitución Política de los Estados Unidos Mexicanos, Texto vigente, última reforma publicada DOF 24-02-2017, Artículo 18, $2^{\circ}$ párrafo. Cursivas mías. 
- pese a su carácter fundamental - son degradados a medios junto a los demás derechos fundamentales no restringidos por la pena, esto, porque su respeto y ejercicio se subordina al logro de la reinserción del sentenciado a la sociedad. Equívoco producto de una magra definición de la reinserción social, supeditada a una justificación reformista de la personalidad dada a la pena privativa de la libertad.

Así, tenemos una redacción constitucional federal que incorpora lo dispuesto en la legislación internacional revisada y que no logra superar las deficiencias apuntadas con anterioridad. No obstante, ¿qué sucede en el caso de la Constitución de la Ciudad de México, considerando se trata de un documento del Siglo XXI? Su definición y claridad acerca de los derechos humanos es muy avanzada en contraste con la Constitución Federal que -pese a sus continuas actualizaciones - se remonta a principios del siglo pasado, lo cual implica limitaciones difícilmente subsanables con enmiendas. No así el caso de la nueva carta fundacional de la Ciudad de México, que sobre el tema de nuestro interés dispone:

Artículo 11. Ciudad incluyente

A. Grupos de atención prioritaria

La Ciudad de México garantizará la atención prioritaria para el pleno ejercicio de los derechos de las personas que debido a la desigualdad estructural enfrentan discriminación, exclusión, maltrato, abuso, violencia y mayores obstáculos para el pleno ejercicio de sus derechos y libertades fundamentales.

\section{B. Disposiciones comunes}

1. Las autoridades de la Ciudad adoptarán las medidas necesarias para promover, respetar, proteger y garantizar sus derechos, así como para eliminar progresivamente las barreras que impiden la realización plena de los derechos de los grupos de atención prioritaria y alcanzar su inclusión efectiva en la sociedad (...)

4. Las autoridades deberán actuar con debida diligencia para prevenir, investigar, sancionar y reparar las violaciones a los derechos humanos, tomando en cuenta la situación y condiciones de vulnerabilidad de cada grupo (...)

6. La ley preverá un sistema integral de asistencia social a cargo de diseñar y ejecutar políticas públicas para la atención de personas, familias, grupos y comunidades con perspectiva de derechos humanos y resiliencia.

L. Derechos de las personas privadas de su libertad

Las personas privadas de su libertad tendrán derecho a un trato humano, a vivir en condiciones de reclusión adecuadas que favorezcan su reinserción social y familiar, a la seguridad, al respeto de su integridad física y mental, a una vida libre de violencia, a no ser torturadas ni víctimas de tratos crueles, inhumanos o degradantes y a tener contacto con su familia ${ }^{20}$.

Una constitución centrada en el reconocimiento, promoción, respeto y garantía de los derechos humanos, contempla la existencia y necesidad de proteger a los grupos vulnerables; en tal sentido, en la Constitución de la Ciudad de México se reconoce por primera vez la vulnerabi-

\footnotetext{
${ }^{20}$ Asamblea Constituyente De La Ciudad De México, Constitución Política de la Ciudad de México, Aprobada en sesión solemne el 31 de enero de 2017 y publicada en la Gaceta Oficial de la Ciudad de México y en el Diario Oficial de la Federación el 5 de febrero de 2017. Las cursivas son mías.
} 
lidad de los reclusos en las prisiones al incluirlos dentro de los grupos de atención prioritaria; esto, en función de la desigualdad estructural que, en su caso, viven en el encierro, lo cual los torna en personas a las que debe garantizarse el pleno ejercicio de sus derechos $(. . .)^{21}$.

En esa ruta, además -en el apartado $L$ - se puntualizan garantías especialmente importantes para ellos, como la seguridad, el respeto a su integridad física y mental, a una vida libre de violencia, sin tortura ni tratos crueles, así como a que se mantengan en contacto con sus familiares $^{22}$. Y en cuanto a la reinserción social, es posible afirmar que se avanza hacia definirla en calidad de derecho fundamental, por lo siguiente:

$1^{\circ}$, En el numeral 1 del apartado "B. Disposiciones Comunes", se ordena eliminar progresivamente las barreras que impiden la realización plena de los derechos de los grupos de atención prioritaria y alcanzar su inclusión efectiva en la sociedad. Con ello se reconoce y define un derecho de prestación, pues el Estado se obliga a hacer lo conducente (eliminar barreras, que en el caso de los reclusos - de modo imperativo- implica modificar a fondo el régimen penitenciario) no sólo para la práctica de los derechos que como seres humanos y grupo vulnerable poseen, sino, en particular, del derecho a la inclusión efectiva (léase, reinserción) social. Y aunque dicha inclusión sea referida como meta, en realidad tiene carácter de derecho fundamental reclamable por los integrantes de cualesquiera de los grupos de atención prioritaria, pues su práctica involucra el abandono de la exclusión vejatoria por ellos padecida y, por ende, una inclusión (reinserción) social dignificante que posibilite la recuperación y fortalecimiento de su integridad personal deteriorada. En el caso de los reclusos, por consiguiente, también incluye proveerles de más y mejores posibilidades de contacto con la vida social exterior.

$2^{\circ}$, Relacionado con lo anterior, en el numeral 6 , de igual manera, es posible ubicar parte del reconocimiento y definición del derecho a la reinserción social, al prescribir la creación de un sistema integral de asistencia a cargo de diseñar políticas públicas de atención con perspectiva de derechos humanos y resiliencia. Esto, para los reclusos y exreclusos, implica el reconocimiento de que la prisión, contrario a lograr reformarlos, les daña física y mentalmente, y que -por lo tanto- es imperioso asistirlos durante y al término de la sanción para amortiguar las secuelas de la pena y apoyar su resiliencia, esto es, la adaptación menos lesiva y recuperación ante el perjuicio infligido por la aplicación penal.

Todo esto significa un viraje en el sentido dado a la pena privativa de libertad. De una institución organizada para administrar tratamientos dirigidos a la reforma de los condenados y la disminución de su reincidencia delictiva, a otra que revela centrarse en proteger los derechos de las víctimas del delito, pero también los de los reclusos. Para las primeras, porque el derecho penal en general, y la pena privativa de libertad en particular, son una garantía de protección a sus derechos fundamentales que se activa cuando las garantías primarias han fallado en tal cometido $^{23}$. En cuanto a los segundos, porque en el encierro pasan de victimarios a víctimas del

\footnotetext{
${ }^{21}$ Ibídem, Artículo 11, apartado A.

${ }^{22}$ Lo que en el apartado "L" se enuncia como derechos -en este caso, considerables también como derechos de prestación-, en sentido estricto y a la luz de la teoría garantista, son garantías de los reclusos, es decir, obligaciones del Estado de crear y mantener las condiciones necesarias para salvaguardar la integridad física y mental de éstos.

${ }^{23}$ Garantías primarias son aquellas otorgadas directamente a nivel constitucional para proteger el ejercicio de los derechos fundamentales ahí reconocidos, las garantías secundarias son “(...) las obligaciones de reparar o sancionar judicialmente las lesiones de los derechos, es decir, las violaciones de sus garantías primarias.” FERRAJOLI, Luigi (2004), Derechos y garantías. La ley del más débil, Madrid, Trotta, $4^{\mathrm{a}}$ ed., p. 43.
} 
sistema de justicia penal ${ }^{24}$. Se convierten en personas en situación de vulnerabilidad a quienes es menester proteger de los efectos de la aplicación penal a través de la salvaguarda a su integridad y dignidad humanas, y dándoles todo el apoyo posible para auxiliarlos en su proceso de resiliencia -entendiendo por ésta, la capacidad de adaptación de un ser vivo frente a un agente perturbador o un estado o situación adversos ${ }^{25}$.

Como puede apreciarse, existe la posibilidad de concebir a la reinserción social como un derecho fundamental (de prestación) y no como finalidad de la pena. Realizable por completo para el caso de los exreclusos, y exigible en el de los internos cuando la aplicación de la pena constituye un límite al derecho a la libertad impuesto proporcionalmente ${ }^{26}$. Pero también, por su parte, en el de aquellos reclusos con sentencias altamente prolongadas (quienes difícilmente obtendrán su libertad), en el sentido de que tienen el derecho a vivir en circunstancias lo más cercanas, similares, a las existentes en la vida social del exterior -lo cual, en cierta medida, significa incluirlos en lugar de excluirlos de ésta ${ }^{27}$.

Finalmente, por lo argumentado, procede afirmar que en la redacción de este texto constitucional no existe el sentido teleológico presente en los demás documentos previamente revisados. Y puede reconocerse, en cambio, el carácter implícito de derecho fundamental aun insuficientemente definido, pero presente que posee la reinserción social.

\section{La reinserción social en la Ley Nacional de Ejecución Penal}

Aunque la ley reglamentaria de la Constitución Política de los Estados Unidos Mexicanos presenta avances significativos en materia de ejecución penal, con respecto a las leyes que le precedieron en los niveles federal y local, parcialmente se mantiene en la línea teleológica marcada constitucionalmente respecto de la reinserción social. Podemos observarlo en lo que sigue:

\section{Artículo 14. De la Autoridad Penitenciaria}

La Autoridad Penitenciaria organizará la administración y operación del Sistema Penitenciario sobre la base del respeto a los derechos humanos, el trabajo, la capacitación para el mismo, la educación, la salud y el deporte, como medios para procurar la reinserción de la persona sentenciada a la sociedad y procurar que no vuelva a delinquir $(. . .)^{28}$.

Como advertimos en el análisis de la legislación internacional e hicimos mención en el caso de la Constitución Federal, la reinserción social es concebida como una finalidad, objetivo o

\footnotetext{
${ }^{24}$ Cfr, Enríquez Rubio Hernández, Herlinda y Hernández Cuevas, Maximiliano (2016), “Víctimas del sistema de justicia penal. La vulnerabilidad de los penados y sus derechos” en ZAMOra Grant, José y GARCÍA MERCADER, Emilio José (Coords.), Acceso a la justicia a víctimas del delito y violaciones a los derechos humanos en Iberoamérica, Murcia España, Diego Marín Editor, pp. 329-373; Ferrajoli, Luigi (1995), op. cit., nota 2, pp. 331-336; Ferrajoli, Luigi (2009), El garantismo y la filosofía del derecho, Bogotá, Universidad Externado de Colombia, pp. 120-131; HernándeZ, Maximiliano (2011), op. cit., nota 2, pp. 149-169.

${ }^{25}$ Real Academia Española (RAE), Diccionario de la Lengua Española (2018).

${ }^{26}$ Es decir, cuando la restricción al derecho a la libertad resiste el "test" de proporcionalidad.

27 Por ejemplo, dotar a la vida en reclusión de circunstancias en que los reclusos pudieran ejercer derechos fundamentales en la actualidad limitados o francamente cancelados con la pena, como el derecho al voto o al ejercicio legal de una profesión. La práctica de tales derechos ampliaría significativamente la posibilidad de realizar proyectos de vida que les facilitaría dar un sentido social incluyente a sus vidas, aun dentro de la cárcel.

${ }^{28}$ Cámara De Diputados Del H. Congreso De La Unión, Ley Nacional de Ejecución de Sanciones, texto vigente, publicada el 16 de junio de 2016.
} 
propósito por alcanzar, lo mismo que la no reincidencia delictiva. Pero aquí, podemos añadir que dicha aspiración se maneja más en calidad de intención, ya que se emplea reiteradamente el término procurar, es decir, que la autoridad penitenciaria debe organizar la administración y operación del Sistema Penitenciario para procurar, intentar, hacer esfuerzos, para lograr la reinserción y la no reincidencia. Por lo demás, lo analizado más arriba se aplica a la ley de ejecución, es decir, se degrada a medio el respeto y la práctica de los derechos humanos, al supeditarlos a la intención de alcanzar la reinserción social y la no reincidencia.

No obstante, conviene destacar que en esta ley reglamentaria por fin se define el concepto de reinserción social: Reinserción social. Restitución del pleno ejercicio de las libertades tras el cumplimiento de una sanción o medida ejecutada con respeto a los derechos humanos ${ }^{29}$. Y que tal concepto es concebido en calidad de principio rector del Sistema Penitenciario, junto con otros principios.

¿Hacia dónde puede conducir este posicionamiento? Por un lado, como principio, el concepto de reinserción social es de carácter deóntico y no axiológico, por lo cual no cabe darle un significado finalista. Y esto, acaso, puede explicar por qué se enuncia -en un intento muy comprometido y mal logrado de evitar el sentido teleológico-, como acabamos de observar en el artículo 14 recién citado, que la autoridad penitenciaria procurará, esto es, intentará la reinserción social. Lo cual resulta antagónico a la ubicación de esta última como principio.

Por otro lado, al tener la reinserción social el carácter de principio es posible concebirla como derecho fundamental conforme a la teoría de los derechos fundamentales ${ }^{30}$, considerando lo siguiente:

I. Su primer nivel de definición es dado como disposición de derecho fundamental puesta en el artículo 18 de la carta magna, que la conceptualiza difusamente aún como finalidad: El sistema penitenciario se organizará (...) para lograr la reinserción del sentenciado a la sociedad y procurar que no vuelva a delinquir ${ }^{31}$.

II, Un segundo nivel de definición, le proporciona el carácter de norma de derecho fundamental al posicionarla como principio rector del sistema penitenciario: Reinserción social. Restitución del pleno ejercicio de las libertades tras el cumplimiento de una sanción o medida ejecutada con respeto a los derechos humanos.

Es de esta manera como la teoría da cuenta de un derecho fundamental, cuya configuración completa se integra con dos niveles de definición, el primero, con la disposición de derecho fundamental enunciada constitucionalmente, y, el segundo, con su porción definitoria reglamentaria, la norma de derecho fundamental. Juntos, ambos contenidos normativos definen al derecho en cuestión. En este caso, el derecho a la reinserción social.

Podrá objetarse que en el primer nivel la reinserción no está dotada como principio, sino como finalidad. Sin embargo, una constitución, en sentido estricto, dispone principios no valores -aun cuando a menudo se haga un uso indiscriminado de términos en tal sentido. El rasgo

\footnotetext{
${ }^{29}$ Ibídem, Artículo 4. Principios Rectores del Sistema Penitenciario.

30 Sobre la conformación de los derechos fundamentales véase, AlEXy, Robert (1993), op. cit., nota 10, pp. 48-172; y Bernal Pulido, Carlos (2014), El principio de proporcionalidad y los derechos fundamentales, Bogotá, Universidad Externado de Colombia, $4^{\mathrm{a}}$ ed., capítulo 1.

${ }^{31}$ Cámara De Diputados Del H. Congreso De La Unión, Constitución Política de los Estados Unidos Mexicanos, Texto vigente, última reforma publicada DOF 24-02-2017.
} 
distintivo de una Constitución es precisamente establecer principios que, por supuesto, tienen carga valorativa, pero el sentido y su fuerza está en su esencia deontológica.

La segunda fase de integración del derecho fundamental, en el caso de la ley de ejecución, claramente lo termina de delinear al precisarlo y dejarlo establecido como principio, pese a los desaciertos puestos más adelante, entre otros, en su artículo 14.

Ahora bien, las derivaciones que pueden hacerse de concebir a la reinserción social, bien como finalidad o en su calidad de derecho fundamental, llevan una carga problemática que es necesario no desdeñar por sus fuertes implicaciones.

\section{La pena privativa de la libertad y la reinserción social ante el examen de proporcionalidad}

El problema de que la reinserción social sea tratada legalmente como un fin de la pena de prisión se hace evidente cuando esta última es sometida a un examen de proporcionalidad, por medio del cual se busca responder a lo siguiente: ¿Qué tan adecuada, necesaria y racional en sentido estricto es la pena impuesta como restricción al derecho a la libertad? ¿Es viable concebir que los penados podrán reinsertarse a la sociedad, en los términos que se plantean normativamente, cuando sus sentencias son altamente prolongadas?

El principio o máxima de proporcionalidad ${ }^{32}$ es un instrumento jurídico empleado para examinar qué tan proporcional o razonable es el límite impuesto a un derecho fundamental (en nuestro caso por la pena privativa de la libertad). Ordena que toda norma regulatoria limitante de un derecho fundamental debe ser razonable, es decir, proporcional ${ }^{33}$, lo cual sucede si tal regulación respeta los tres subprincipios o condiciones de razonabilidad siguientes:

1. Adecuación o idoneidad, prescribe que las normas reguladoras deben ser idóneas para alcanzar el fin que se busca con su cumplimiento. En nuestro caso, acorde a la Constitución y la Ley Nacional de Ejecución Penal, tal fin es la reinserción social y la no reincidencia delictiva. Es decir, establecido el fin que busca el legislador y el medio que emplea, debe verificarse que este último resulta apto para el logro del primero ${ }^{34}$. Tal verificación consiste en constatar que la pena de prisión, en efecto, no imposibilite la realización de la reinserción social aun cuando sea en un solo caso, pues se trata de restricción de derechos fundamentales. Y es aquí cuando encontramos que dicha sanción no es totalmente adecuada para conseguir la finalidad constitucional, si se toma en cuenta que leyes especiales ordenan sentencias hasta por ochenta, noventa y cien años ${ }^{35}$. Pena

\footnotetext{
32 Sobre el tema véase, Alexy, Robert (1993), op. cit., nota 10, pp. 11-137; Alexy, Robert (2011), "Los derechos fundamentales y el principio de proporcionalidad”, Revista Española de Derecho Constitucional, núm. 91, enero-abril, pp. 11-29; Bernal Pulido, Carlos (2014), op. cit., nota 29, capítulo 1; Cianciardo, Juan (2003), "El subprincipio de necesidad y el control constitucional de razonabilidad", El derecho, Argentina, Sistema Argentino de Información Jurídica, pp. 185-198. En línea. Disponible en: https://riu.austral.edu.ar/bitstream/handle/123456789/482/ El-subprincipio-de-necesidad-y.pdf?sequence=1 (consultada el 31 de enero de 2019); Clérico, Laura (2015), "El examen de proporcionalidad: entre el exceso por acción y la insuficiencia por omisión o defecto", en CARBONELL, Miguel (Comp.), Argumentación jurídica. El juicio de ponderación y el principio de proporcionalidad, México, Porrúa, pp. 113-153.

${ }^{33}$ Cfr. Cianciardo, Juan (2003), op. cit., nota 32.

${ }^{34}$ Ibídem, p. 1.

35 Por ejemplo, Cámara De Diputados Del H. Congreso De La Unión, Ley General para Prevenir y Sancionar los Delitos en Materia de Secuestro, Reglamentaria de la fracción XXI del artículo 73 de la Constitución Política de los Estados Unidos Mexicanos, texto vigente, última reforma publicada DOF 19-01-2018, "Artículo 9. Al que prive de la libertad a otro se le aplicarán: I. De cuarenta a ochenta años de prisión (...) Artículo 10. Las penas a que se refiere el artículo 9 de la presente Ley, se agravarán: I. De cincuenta a noventa años de prisión y de cuatro mil a ocho mil días multa, si en la privación de la libertad concurre alguna o algunas de las circunstancias 
de prisión que de hecho es cadena perpetua. Una antinomia del fin de la reinserción social que compromete la superación satisfactoria del test de idoneidad, pese a la opinión más indulgente de algunos especialistas ${ }^{36}$.

2. Necesidad, que también, desde la perspectiva fáctica, examina si el límite impuesto -en nuestro caso - al derecho a la libertad por la pena de prisión, realmente es el necesario o existen mejores alternativas para intervenirlo con menor perjuicio, igualmente encaminadas al fin de la reinserción social.

Con certeza, para muchos reclusos aplicarían otras penas restrictivas del derecho a la libertad menos nocivas que la prisión, como el tratamiento en libertad de imputables, la semilibertad y el trabajo a favor de la víctima o de la comunidad ${ }^{37}$, dado que gran parte de la población penitenciaria está presa por delitos no graves: Según la Encuesta Nacional Penitenciaria (ENPOL 2016) $)^{38}$, el 73. 9\% de los reclusos en México son presos sin antecedentes penales y un $25.9 \%$ son reincidentes. Asimismo, en más del 50 \% la duración de sus sentencias es entre o y 10 años de prisión, en el 20.2\% entre 11 y 19 años, y sólo un 25.7\% tiene sentencias de 20 o más años. ¿Qué significado cabe darle a esta información? Entro otros, que la mayoría de los sentenciados a pena de prisión podrían estar mejor y menos dañados en penas alternativas, también dirigidas a cumplir con el fin de la reinserción social. En efecto, conviene añadir que la institución carcelaria es en extremo mortificante y lesiva de la integridad de los penados, por lo cual no puede

siguientes: Párrafo reformado DOF o3-06-2014 (...) II. De cincuenta a cien años de prisión (...) Las sanciones señaladas en el presente artículo se impondrán, sin perjuicio o con independencia de las que correspondan por otros delitos que de las conductas a las que se aplican resulten." Cursivas mías.

${ }^{36}$ Por ejemplo: “(...) normalmente el medio adoptado por el legislador buscará por lo menos realizar sus fines en alguna medida. Esto basta para superar el test de idoneidad. Por esta razón, la relevancia práctica del subprincipio de idoneidad es más bien baja." Alexy, Robert (2011), op. cit., nota 31, p.14.

37 Cámara De Diputados Del H. Congreso De la Unión, Código Penal Federal, texto vigente, última reforma publicada DOF, 9-03-2018, "Artículo 27.- El tratamiento en libertad de imputables consistente en la aplicación de las medidas laborales, educativas y curativas, en su caso, autorizadas por la ley y conducentes a la reinserción social del sentenciado, bajo la orientación y cuidado de la autoridad ejecutora. Su duración no podrá exceder de la correspondiente a la pena de prisión sustituida. La semilibertad implica alternación de períodos de privación de la libertad y de tratamiento en libertad. Se aplicará, según las circunstancias del caso, del siguiente modo: externación durante la semana de trabajo o educativa, con reclusión de fin de semana, salida de fin de semana, con reclusión durante el resto de ésta; o salida diurna, con reclusión nocturna. La duración de la semilibertad no podrá exceder de la correspondiente a la pena de prisión sustituida. El trabajo en favor de la comunidad consiste en la prestación de servicios no remunerados, en instituciones públicas educativas o de asistencia social o en instituciones privadas asistenciales. Este trabajo se llevará a cabo en jornadas dentro de períodos distintos al horario de las labores que representen la fuente de ingreso para la subsistencia del sujeto y de su familia, sin que pueda exceder de la jornada extraordinaria que determine la ley laboral y bajo la orientación y vigilancia de la autoridad ejecutora. El trabajo en favor de la comunidad puede ser pena autónoma o sustitutivo de la prisión o de la multa. Cada día de prisión será sustituido por una jornada de trabajo en favor de la comunidad. La extensión de la jornada de trabajo será fijada por el juez tomando en cuenta las circunstancias del caso. Por ningún concepto se desarrollará este trabajo en forma que resulte degradante o humillante para el sentenciado."; véase también, para el fuero común, Asamblea Legislativa Del Distrito Federal, Código Penal del Distrito Federal, texto vigente, última reforma publicada en la Gaceta Oficial de la Ciudad de México, el 31 de diciembre de 2018, Artículos 34, 35 y 36. Cursivas mías.

${ }^{38}$ Instituto Nacional de Estadística y Geografía, Encuesta Nacional Penitenciaria (ENPOL) 2016. En línea. Disponible en: https://www.inegi.org.mx/programas/enpol/2016/ (consultada el 2 de abril de 2019). 
cumplir con programas y planes que coadyuven a la reinserción social39. Podemos observar así, que la pena de prisión tampoco supera la exigencia del subprincipio de necesidad.

3. Proporcionalidad en sentido estricto, consiste en establecer si el límite impuesto (pena de prisión) resulta razonable con respecto al fin que se persigue (reinserción social). Es en este punto, donde normativamente aflora el error jurídico de relacionar a la pena de prisión con el fin de la reinserción ${ }^{40}$. ¿Debe prevalecer el interés de proteger, garantizar, los derechos de las víctimas del delito o el interés de reinsertar socialmente al delincuente? Si el fin de la prisión es la reinserción social de éste ¿cómo queda el interés o finalidad de proteger los derechos de aquéllas?

Además, adviértase que no sólo de manera fáctica -como se vio en los exámenes de los anteriores subprincipios-, sino también legislativamente, el fin de la reinserción social no puede ser cumplido para los casos de sentencias prolongadas, pese a su prescripción a nivel constitucional y lo que se reglamenta en la Ley Nacional de Ejecución Penal. Como se aprecia, normativamente la pena de prisión tampoco supera el test de estricta razonabilidad, cuando el fin que se persigue con ella es la reinserción social.

Podrá inferirse de lo precedente, que es preferible - más razonable-colocar como fin y justificación de la pena privativa de la libertad a la protección de los derechos de las víctimas y de la sociedad en general ${ }^{41}$, pues con ello se evita el callejón sin salida mostrado y, en cambio, se hace posible reivindicar el derecho fundamental de los reclusos a la reinserción social en su calidad de principio y no de finalidad, siempre que la restricción impuesta sobre éste no lo impida, lo cual es motivo de otro debate.

\section{Conclusiones}

$\mathbf{1}^{\mathbf{a}}$ Este estudio ha contribuido a demostrar que es posible concebir a la reinserción social como derecho fundamental, aun cuando equívocamente se le da tratamiento legislativo de finalidad no sólo en nuestro país, sino también en algunos documentos internacionales sobre el tema. No obstante, son notables los avances aportados por la Constitución de la Ciudad de México.

$2^{a}$ El único fin y justificación de la pena de prisión admisible desde una postura garantista es proteger los derechos fundamentales, en particular de las víctimas del delito; que cumpla su función de garantía secundaria cuando las garantías primarias de protección a los derechos fun-

\footnotetext{
${ }^{39}$ Acerca de estudios que prueban la lesividad de la pena de prisión y la ineficacia de los programas de reinserción social, véase Enríquez Rubio Hernández, Herlinda (2016), op. cit., nota 2, capítulos 2,3 y anexos II y III; Hernández Cuevas, Maximiliano (2011), op. cit., nota 2, capítulos 4, 5, 6 y Anexo I; Enríquez Rubio Hernandez, Herlinda y Hernández Cuevas, Maximiliano (2015), "Derecho ilegítimo en la prisión: morir dignamente o vivir sin derechos”, Revista Andamios, núm. 27, enero-abril, 2015, pp. 237-256. En línea. Disponible en: https:// andamios.uacm.edu.mx/index.php/andamios/issue/archive (consultada el 2 de febrero de 2019).

40 "Las llamadas "antinomias de los fines de la pena" surgen cuando el Derecho penitenciario — en verdad una parte y prolongación del Derecho penal y del Derecho procesal penal en la realidad de las consecuencias jurídicas- desarrolla, por su parte, y claramente favorece una determinada meta de la pena: la resocialización. Los problemas de armonización que esto puede crear con la conminación penal y la fase de medición de la pena son evidentes, ya que en estas otras fases dominan otros fines el centro de su interés." Hassemer, Winfried y MuÑoz Conde Francisco (1989), op. cit., nota 2, p. 134.

${ }^{41}$ Como de alguna forma se hace en las Reglas Mandela. 
damentales han sido rebasadas por el delito. Como quedó demostrado, si se le adjudica como fin la reinserción social, la aplicación penal no resiste un examen de proporcionalidad.

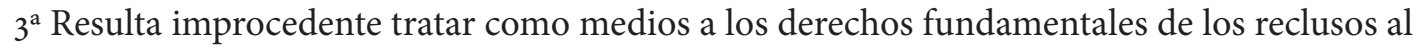
dirigir, condicionar su práctica al logro de la reinserción social, dado que son principios. Ésta es otra inconsistencia de la Constitución Federal.

$4^{\text {a }}$ Aunque la definición de la reinserción social es difusa y contradictoria en la Constitución federal, es viable entenderla ya como derecho de los reclusos más que como fin de la pena gracias a su porción complementaria dada en la Ley Nacional de Ejecución Penal, que la define y establece como su principio rector. Con ello se reúnen dos requisitos básicos de integración de un derecho fundamental: el primero, en la Constitución como disposición de derecho fundamental, y el segundo, en la citada ley en calidad de norma de derecho fundamental.

$5^{\text {a }}$ La reinserción social, estrictamente, desde una postura deontológica, y por ende garantista, es un principio constitucional más que un fin de la pena. Por lo mismo, un derecho de prestación que obliga al Estado a realizar lo conducente para rehabilitarle al penado su derecho a la libertad, junto con los demás derechos que le fueron suspendidos con la pena, tras el cumplimiento de su condena o bien al otorgarle los beneficios que la ley le otorga.

$6^{a}$ Como derecho de prestación realizable aún en el encierro, particularmente en lo concerniente a los presos con sentencias prolongadas, el Estado también está obligado a garantizarles condiciones de vida lo más cercanas a las existentes en la sociedad exterior, de modo que puedan ejercer, aun con ciertas restricciones, varios de los derechos que actualmente les han sido suspendidos. Tal es el sentido de la práctica de sus derechos y no el de tratamiento reformista. El derecho a la reinserción social se realiza no sólo cuando la persona abandona la prisión, sino que su práctica también involucra que las personas recobren un sentido de vida digno.

\section{Bibliografía}

Alexy, Robert (2011), "Los derechos fundamentales y el principio de proporcionalidad", Revista Española de Derecho Constitucional, núm. 91, enero-abril, pp. 11-29.

(1993), Teoría de los derechos fundamentales, Madrid, Centro de Estudios Constitucionales.

BARATta, Alessandro (2004), Criminología crítica y crítica del derecho penal. Introducción a la sociología jurídico-penal, Buenos Aires, Siglo XXI, $1^{\text {a }}$ ed., $1^{\text {a }}$ Reimpresión.

BAstida, Francisco et al. (2004), Teoría General de los Derechos Fundamentales en la Constitución Española de 1978, Madrid. Disponible en: https://www.unioviedo.es/constitucional/ miemb/alaez/librodf.PDF (consultada el 31 de enero de 2019)

Bernal Pulido, Carlos (2014), El principio de proporcionalidad y los derechos fundamentales, Bogotá, Universidad Externado de Colombia, $4^{\mathrm{a}}$ ed.

ClériCo, Laura (2015), "El examen de proporcionalidad: entre el exceso por acción y la insuficiencia por omisión o defecto", en Carbonell, Miguel (Comp.), Argumentación jurídica. El juicio de ponderación y el principio de proporcionalidad, México, Porrúa, pp. $113-153$. 
Cortina, Adela (2000), Ética mínima. Introducción a la filosofía práctica, Madrid, Tecnos, $6^{\text {a }}$ ed.

Cianciardo, Juan (2003), "El subprincipio de necesidad y el control constitucional de razonabilidad”, El derecho, Argentina, Sistema Argentino de Información Jurídica, pp. 185-198. En línea. Disponible en: https://riu.austral.edu.ar/bitstream/handle/123456789/482/Elsubprincipio-de-necesidad-y.pdf?sequence $=1$ (consultada el 31 de enero de 2019).

Cullen, Francis y Gendreau (2006), Paul "Evaluación de la rehabilitación correccional: política, prácticas y perspectivas”, en BARBERET, Rosemary y BARQuín, Jesús, Justicia penal siglo XXI. Una selección criminal justice 2000, Granada, National Institute of Justice (U.S. Department of justice).

Enríquez Rubio Hernández, Herlinda y Hernández Cuevas, Maximiliano, "Víctimas del sistema de justicia penal. La vulnerabilidad de los penados y sus derechos" en Zamora Grant, José y García Mercader, Emilio José (Coords. 2016), Acceso a la justicia a víctimas del delito y violaciones a los derechos humanos en Iberoamérica, Murcia España, Diego Marín Editor.

Enríquez Rubio Hernández, Herlinda, (2016), El pluralismo jurídico intracarcelario. El derecho y la ley no escrita de la prisión, México, Porrúa, $2^{\text {a }}$ ed.

Enríquez Rubio Hernández, Herlinda y Hernández Cuevas, Maximiliano (2015), “Derecho ilegítimo en la prisión: morir dignamente o vivir sin derechos", Revista Andamios, núm. 27, enero-abril, 2015, pp. 237-256. En línea. Disponible en: https://andamios.uacm. edu.mx/index.php/andamios/issue/archive (consultada el 2 de febrero de 2019).

Farrel, Martín, “El utilitarismo en la filosofía del derecho”. En línea. Disponible en: https:// archivos.juridicas.unam.mx/www/bjv/libros/8/3876/4.pdf (consultada el 2 de marzo de 2018).

FerRajOli, Luigi (2009), El garantismo y la filosofía del derecho, Bogotá, Universidad Externado de Colombia.

(2004), Epistemología jurídica y garantismo penal, México, Fontamara.

(2004), Derechos y garantías. La ley del más débil, Madrid, Trotta, $4^{\mathrm{a}}$ ed.

(1995), Derecho y razón. Teoría del garantismo penal, Madrid, Trotta.

GARLAND, David, (2005), La cultura del control. Crimen y orden social en la sociedad contemporánea, Barcelona, Gedisa.

Habermas, Jürgen (2005), Facticidad y validez. Sobre el derecho y el Estado democrático de derecho en términos de teoría del discurso, Madrid, Trotta, $4^{\mathrm{a}}$ ed.

Hassemer, Winfried y Muñoz Conde Francisco (1989), Introducción a la criminología y al derecho penal, Valencia, Tirant lo Blanch. 
Hernández Cuevas, Maximiliano (2011), Trabajo y derecho en la prisión. Una relación entre legalidad y normatividad alterna, México, Porrúa.

Instituto Nacional de Estadística y Geografía, Encuesta Nacional Penitenciaria (ENPOL) 2016. En línea. Disponible en: https://www.inegi.org.mx/programas/ enpol/2016/ (consultada el 2 de abril de 2019).

Miralles, Teresa, (1983), "IV Patología criminal: La personalidad criminal”, en Bergali, R, et al, Pensamiento criminológico I: un análisis crítico, Bogotá, Colombia, Temis.

Orellana Wiarco, Octavio (2012), Criminología moderna y contemporánea, México, Porrúa.

Zagrebelsky, Gustavo, El derecho dúctil. Ley, derechos, justicia (1995), Madrid, Trotta

\section{Documentos legislativos}

Código Penal del Distrito Federal, texto vigente, última reforma publicada en la Gaceta Oficial de la Ciudad de México, el 31 de diciembre de 2018.

Código Penal Federal, texto vigente, última reforma publicada Diario Oficial de la Federación, 9-03-2018.

Constitución Política de la Ciudad de México, Aprobada en sesión solemne el 31 de enero de 2017 y publicada en la Gaceta Oficial de la Ciudad de México y en el Diario Oficial de la Federación el 5 de febrero de 2017.

Constitución Política de los Estados Unidos Mexicanos, Texto vigente, última reforma publicada DOF 24-02-2017.

Convención Americana sobre Derechos Humanos (Pacto de San José), San José, Costa Rica, 7 de mayo de 1981.

Ley que Establece las normas Mínimas sobre Readaptación Social de Sentenciados, México, 19 de mayo de 1971.

Ley Nacional de Ejecución Penal, texto vigente, publicada el 16 de junio de 2016.

Ley General para Prevenir y Sancionar los Delitos en Materia de Secuestro, Reglamentaria de la fracción XXI del artículo 73 de la Constitución Política de los Estados Unidos Mexicanos, texto vigente, última reforma publicada DOF 19-01-2018.

Pacto Internacional de Derechos Civiles y Políticos, Nueva York, 1966.

Principios básicos para el tratamiento de los reclusos, Adopción: Asamblea General de la ONU, Resolución 45/111, 14 de diciembre de 1990.

Reglas Mínimas de las Naciones Unidas para el Tratamiento de los Reclusos. Adopción: Consejo Económico y Social de la ONU. Resoluciones 663C (XXIV), del 31 de julio de 1957 y 2076 (LXII), del 13 de mayo de 1977. 
Reglas Mínimas de las Naciones Unidas para el Tratamiento de los Reclusos (Reglas Nelson Mandela), Asamblea General, resolución 70/175, anexo, aprobado el 17 de diciembre de 2015. 